\title{
Proceeding
}

Supplementary Issue: Winter Conferences of Sports Science. Costa Blanca Sports Science Events, 22-23 March 2021. Alicante, Spain.

\section{Primary school physical education in outdoor during COVID-19 pandemic: The perceptions of teachers}

\author{
TIZIANA D'ISANTO $1 \unlhd$, FRANCESCA D'ELIA² \\ ${ }^{1}$ MIUR Campania, Italy \\ 2University of Salerno, Italy
}

\begin{abstract}
In Italy since February 2020 and still currently, schools of all levels throughout the National territory have carried out their activities alternating distance teaching with face-to-face one, with the relative adaptations due to the online and face-to-face mode in compliance with the health safety protocols. Teachers had to make substantial changes to their teaching/learning design and, to deal with this issue, the permanent training activities in service are fundamental. Physical education is one of the teaching subjects that most needs to be adapted in design and outdoor movement education seems to be a good practice to be developed to offer new ideas for teaching/learning planning. The aim is to detect the opinions of primary school teachers in order to offer effective contents of the permanent training about physical education during pandemic and to promote teaching methods of physical education in primary school moreover on outdoor education. The results show how active are teachers, where they practice, how the pandemic and the smart configuration of life affected their lifestyles, what are their perceptions and perspectives about outdoor physical education and its importance for the achievement of children movement development goal. The collected data revealed an high recognition of the contribution that physical education offers to the achievement of skills development goals but at the same time emerge specific training needs in teaching methods of physical education.
\end{abstract}

Keywords: Distance teaching/learning; In-service training; Physical activity levels.

\section{Cite this article as:}

D'Isanto, T., \& D'Elia, F. (2021). Primary school physical education in outdoor during COVID-19 pandemic: The perceptions of teachers. Journal of Human Sport and Exercise, 16(3proc), S1521-S1535. https://doi.org/10.14198/jhse.2021.16.Proc3.67

Corresponding author. MIUR Campania, Italy. http://orcid.org/0000-0001-7151-7486

E-mail: tizidisanto@libero.it

Abstract submitted to: Winter Conferences of Sports Science. Costa Blanca Sports Science Events, 22-23 March 2021. Alicante, Spain.

JOURNAL OF HUMAN SPORT \& EXERCISE ISSN 1988-5202.

(c) Faculty of Education. University of Alicante.

doi:10.14198/jhse.2021.16.Proc3.67 


\section{INTRODUCTION}

The COVID-19 pandemic has imposed substantial changes in many aspects of our lives around the world; in general, the educational systems, especially schools, have had to face the health emergency by significantly modifying ordinary school activities.

In Italy since February 2020 and still currently, schools of all levels throughout the National territory have carried out their activities alternating distance teaching with face-to-face teaching, with the relative adaptations due to the online and face-to-face mode in compliance with the health safety protocols. In starting face-to-face lessons, it has been necessary to ensure the full performance of physical education activities, obviously in compliance with the safety instructions of the Italian Technical Scientific Committee. According to the National Guidelines for the safe management of social and play opportunities for children and adolescents during the COVID-19 emergency, attention is drawn to the right balance between the right to sociality, to play and in general to education of children and adolescents, and, on the other hand, the need to guarantee conditions for the protection of their health. The point of greatest attention concerns, in fact, how to implement conditions that make it possible to offer positive opportunities in the greatest degree of safety possible. The Italian Technical Scientific Committee indicated that "For the recreation and physical activities where possible and compatibly with structural, safety and meteorological variables, we must favour outdoor activities enhancing the outdoor space as an alternative learning opportunity. For Physical Education activities, if carried out indoors, adequate ventilation and an interpersonal distance of at least two meters must be guaranteed. Individual physical sports activities that allow physical distancing are to be favoured". So, teachers had to make substantial changes to their teaching/learning design, in particular physical education is one of the teaching subjects that most needs to be adapted in designing teaching/learning activities. The problem is that physical education, differently from other teaching subjects, has didactic and educational characteristics (Raiola, 2011) that have not been easily "transferable" to distance learning, producing a significant qualitative and quantitative reduction of school experiences of Physical Education and requiring a necessary redesign of teaching methods and learning aims of physical education. Outdoor movement education seems to be a good practice to be developed to offer new ideas for teaching/learning planning and for this purpose the permanent training activities in service are fundamental, so this study aims to detect the opinions of primary school teachers to offer effective contents of the permanent training about physical education.

This is an exploratory study aimed at bringing out the perceptions of teachers about physical education and its importance in teaching/learning processes during childhood and at receiving their training needs in order to adequately design the compulsory permanent training. Previous studies have been realized on teachers' perspectives about contents and learning aim of physical education in Italian pre-school (D'Isanto et al., 2021, D'Elia et al. 2021) and primary school (D'Elia, 2020) and it brought out that:

- Despite a well-defined profile of PE in primary school and the enhancement of its educational values, interventions and investments in favour of PE and sport made, from the perceptions of the teachers emerge some discrepancies between what is declared and expected and what is actually achieved. In particular, teacher training should be reviewed and school organizational issues about PE taught time and facilities should be realistically analysed to highlight the difficulties that teachers encounter and which often prevent the development of the part of the curriculum dedicated to physical education (D'Elia, 2020);

- An high recognition of the contribution that the field of experience of the body and movement offers for the achievement of skills development goals at the end of pre-school but at the same time emerge specific training needs by pre-school teachers in the field of experience "Body and movement" which, 
during childhood, represents the crossroads of children's growth, maturation and development experiences and which can also become an opportunity for teachers and children to be more active, to teach/learn better and stay as well. Teachers must be encouraged to be more physically active both in their free time and during work mostly in outdoor environments (city parks, urban environment, nature, schoolyard etc.) (D'Isanto et al., 2021).

So, a redesign of training courses for general teachers seems to be appropriate and the promotion of a new and broader perspective of the PE must be encouraged to underline the effects on physical, emotional, cognitive, social, health and wellbeing development. It would be useful also to encourage more general teachers to engage a more collaborative approach that take into account the contribution of PE and of the PE expert (D'Elia 2019ab; Invernizzi et al., 2020) to the whole educational process.

According to the studies on the perceptions of primary school teachers about physical activities and to the Italian Technical Scientific Committee guidelines it emerges the need to design the compulsory training also as indoor and outdoor movement education training, so the aim of this study is to detect the expressed opinions about physical activity by primary school teachers. The goal is to investigate about the perception data in order to promote teaching methods of physical education at public primary school moreover on outdoor education. The purpose is also to formulate useful proposals in the university courses of initial training of teachers.

Specifically, they have been investigated the levels of physical activity achieved by the teachers, the impact that the current contingencies due to COVID-19 are determining on the quantity and quality of physical activities carried out, as well as the value that the teachers attribute to outdoor physical experiences for the achievement of the goals expected at the end of primary school, so as to deduce the training needs of teachers and design training courses that meet these needs and are capable to support and to innovate teaching methods of physical education in primary school, expanding the range of physical experiences that can be addressed to children from 6 to 10 years.

\section{METHODS}

The present study is an analysis based on cluster methodology and conducted investigating an homogeneous target to explore the practice physical education in primary school during COVID-19 pandemic, from the perspective of the teachers, with particular attention to the opportunity of practice physical activities in outdoor environment. The group considered in this study is composed by primary school teachers that teach in south Italy primary schools. This preliminary investigation aims to know the opinion, perception, knowledge and specific practice of physical education by primary school teachers in order to understand if there are relationships between the different responses that can be useful to define the contents and activities of the compulsory training activities in service.

A sample of 102 primary school teachers ( $97.1 \%$ female) with a medium-long (decades) service experience, working in schools in the Campania Region took part in the study with an average age of 51.2.

A structured questionnaire was prepared with Google Forms and disseminated by e-mail. The questionnaire was composed by 28 questions. Particular attention has been paid to the data on:

- Personal physical practice

- Barriers or facilities that influence the practice of physical activity

- Perceptions of physical activity and the influence of COVID-19 
- $\quad$ Perceptions of physical activity in relation to the school context

- Outdoor physical activities

Descriptive statistics were used to calculate the variables expressed as a percentage and the chi-square test was used to verify the existence of a relationship between the following variables: personal data, on individual physical activity level, on the possible presence of structural barriers, perceptions on the importance of physical activity, personal teaching experience towards physical activity, on the consequences of COVID-19 on physical activity and on the possibility of practicing outdoor physical activity in primary school. The standard statistical software package (IBM Corp. Released 2020. IBM SPSS Statistics for Windows, Version 27.0. Armonk, NY: IBM Corp) was used. The level of significance was set at $p<.05$.

\section{RESULTS AND DISCUSSION}

The results show how active are teachers, where they practice, how the pandemic and the new "smart" configuration of life affected their lifestyles, what are their perceptions and perspectives about physical education and its importance for the achievement of children development goal at the end of the primary school. Some issues emerged were common with the results of other studies (D'Isanto et al., 2021, D'Elia et al., 2021, Raiola et al., 2021a,b, Raiola et al., 2020).

\section{Data on personal physical practice}

Question 6. Are you physically active? Yes 48\%; Partially 16.7\%; No 35.3\%.
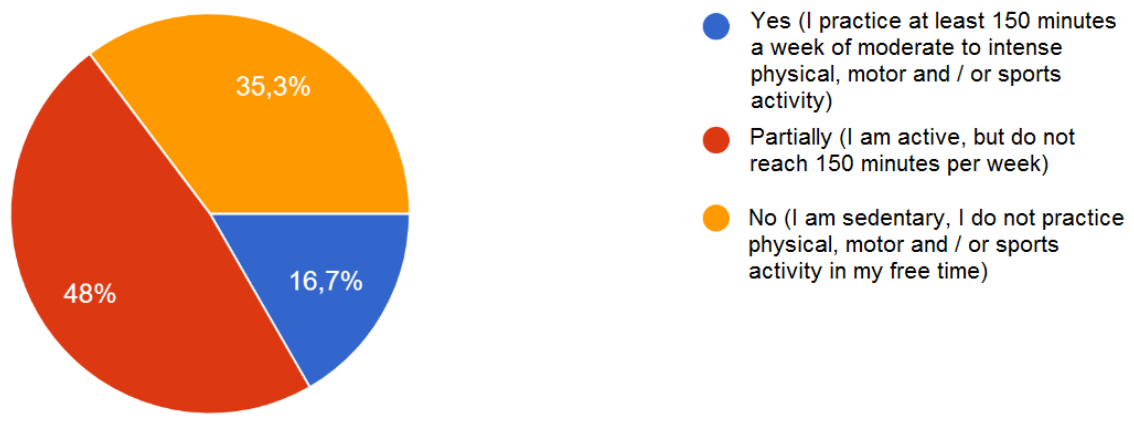

Partially (I am active, but do not reach 150 minutes per week)

No (I am sedentary, I do not practice physical, motor and / or sports activity in my free time)

Figure 1. Level of physical activity.

Question 7. Where do you practice physical activity? (answers of active and partially active) $54.4 \%$ indoor; $45.6 \%$ outdoor.
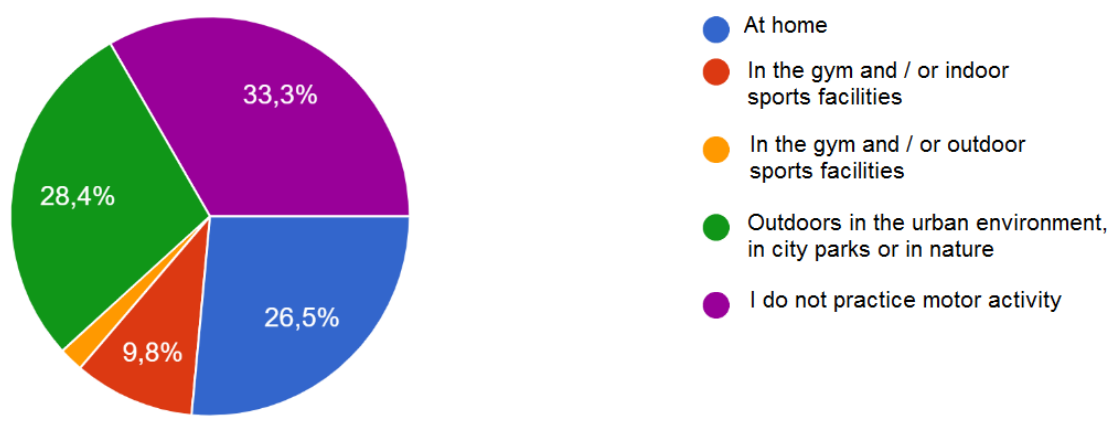

Figure 2. Place of physical activity. 
Question 10. What activity do you usually do? 16.5\% Structured activities; $83.5 \%$ unstructured activities.
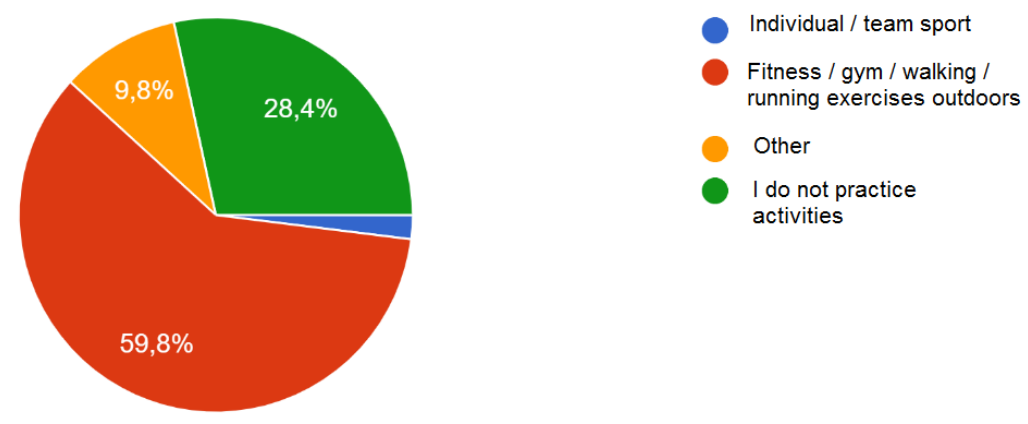

Figure 3. Type of sport/physical activity practiced.

Question 12. How important do you consider the practice of physical and / or sports activity in daily life? 65\% very high.

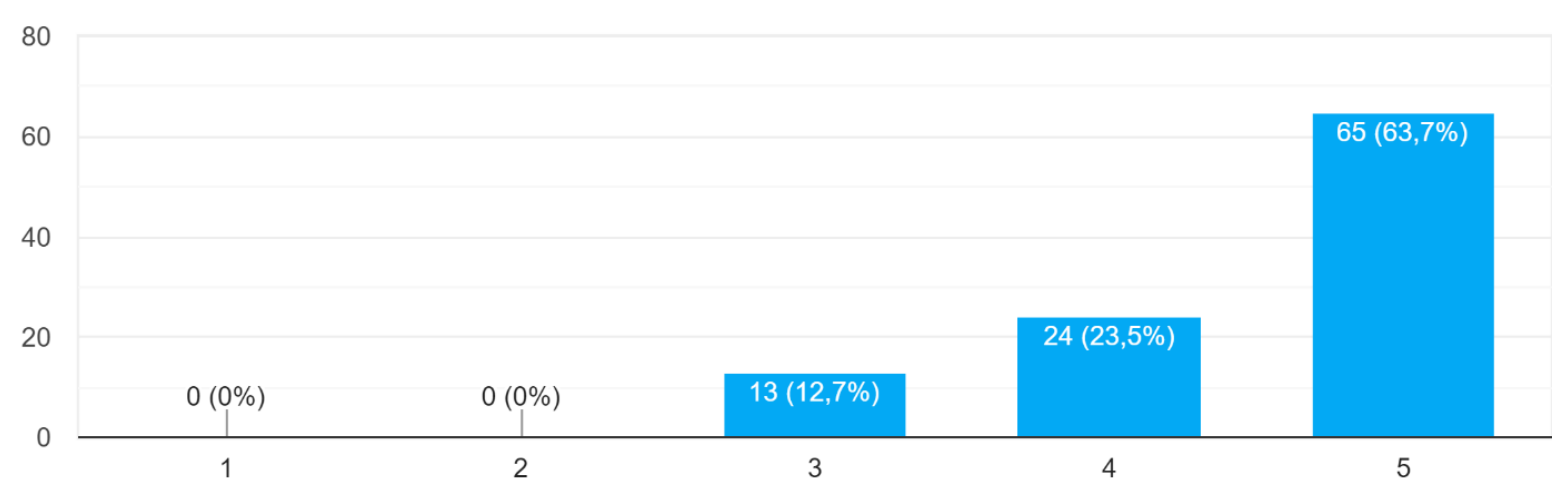

Figure 4. Importance of sport/physical activity in everyday life.

\section{Data on barriers or facilities that influence the practice of physical activity}

Question 8. Are there indoor sports facilities and / or gyms near the area where you live? 93.1\% yes.

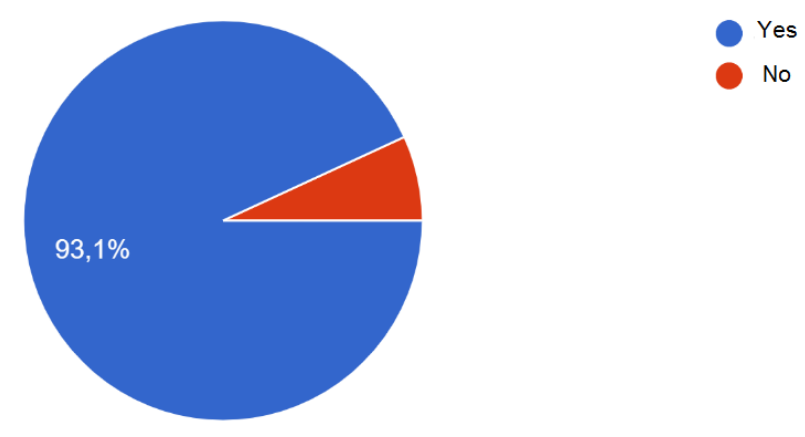

Fig 5. Presence of indoor barriers that influence sport/physical activity

Question 9. Are there pedestrian paths, parks or outdoor sports facilities near the area where you live? $52.9 \%$ no. 


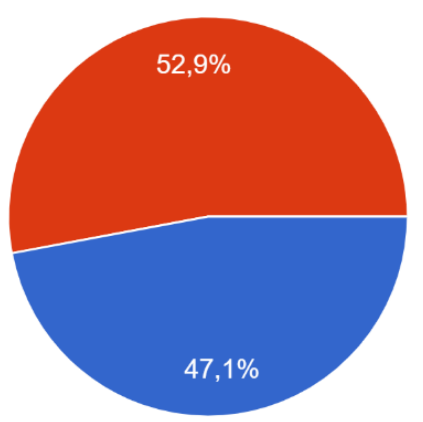

Figure 6. Presence of outdoor barriers that influence sport/physical activity.

\section{Data on perceptions of physical activity and the influence of COVID-19}

Question 11. The current restrictions have affected the quality / quantity of physical activity you carry out? $87.3 \%$ yes.

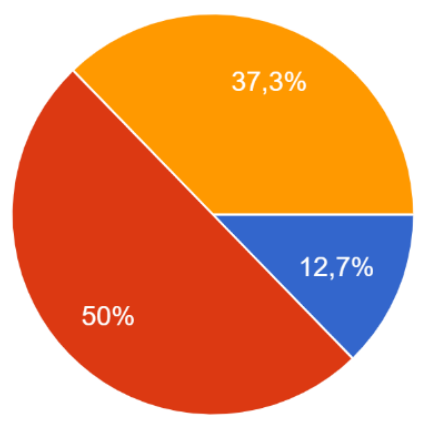

Not at all (I maintained the same levels of physical

Enough (I have reduced physical activity levels)

A lot (l've gone inactive)

Figure 7. Perceptions about restrictions on sport/physical activity.

Question 24. With the current "smart" configurations of work, study and social relations, do you have more free time to devote to physical activity? $87.3 \%$ no.

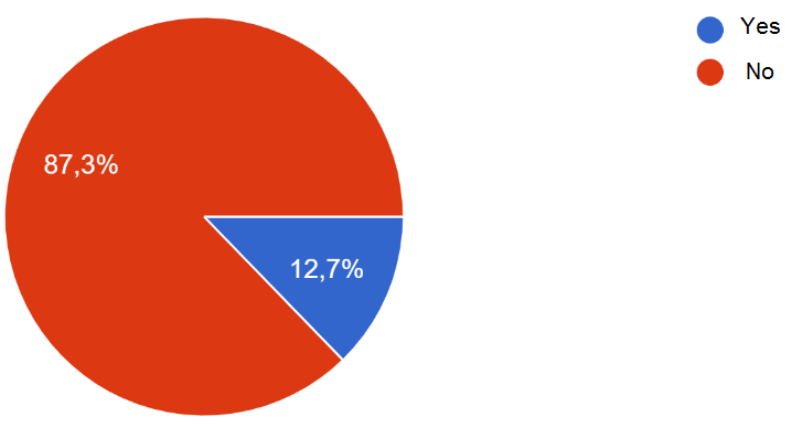

Figure 8. Perceptions of free time with "smart" configurations.

Question 25. How motivated do you feel to engage in physical activity right now? $31.3 \%$ scant; $32.4 \%$ enough; 36.3 high. 


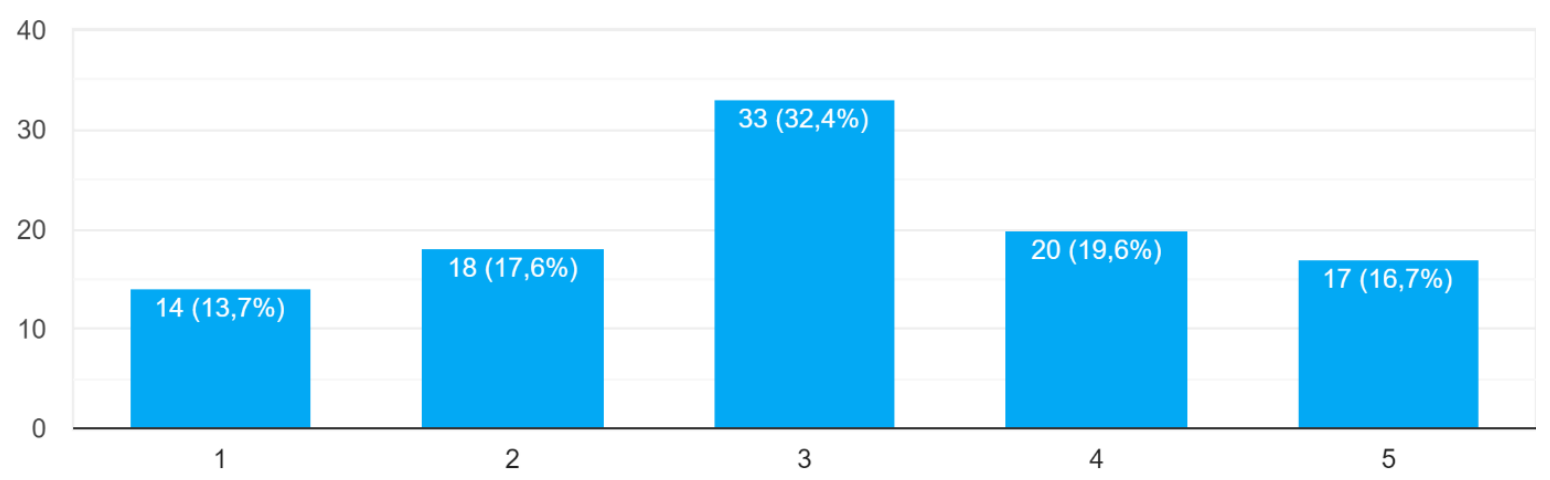

Figure 9. Motivation perceived in practicing sport/physical activity.

Question 26. Which of the following restrictions affects the performance of physical activities the most? $32.4 \%$ closure of gym and facilities; $43.1 \%$ home insulation; $23.5 \%$ social distancing.

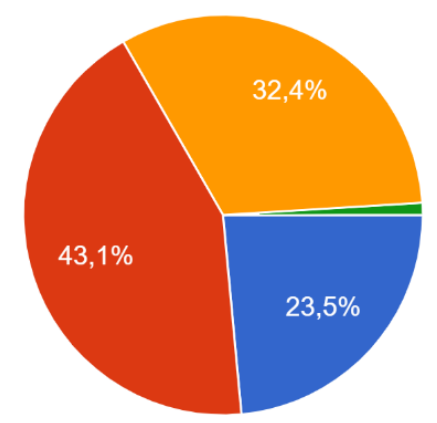

Social distancing

Restriction of circulation

and domestic isolation

Closure of gyms and

sports facilities

Suspension of sporting events

Figure 10. Type of restriction that affected sport/physical practice.

Question 27. Do you think that the practice of physical activity can have beneficial effects against COVID19 ? 74.5 yes; 25.5 no.

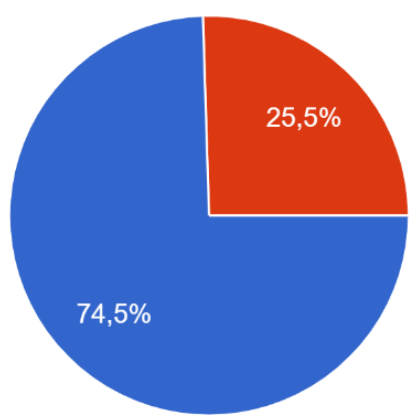

Yes
No

Figure 11. Perceptions on the benefits of physical activity against COVID-19.

Data on perceptions of physical activity in relation to the school context

Question 13. How useful do you think, for the purposes of your in-service training, to study methods and teaching of physical education? $74.5 \%$ very useful. 


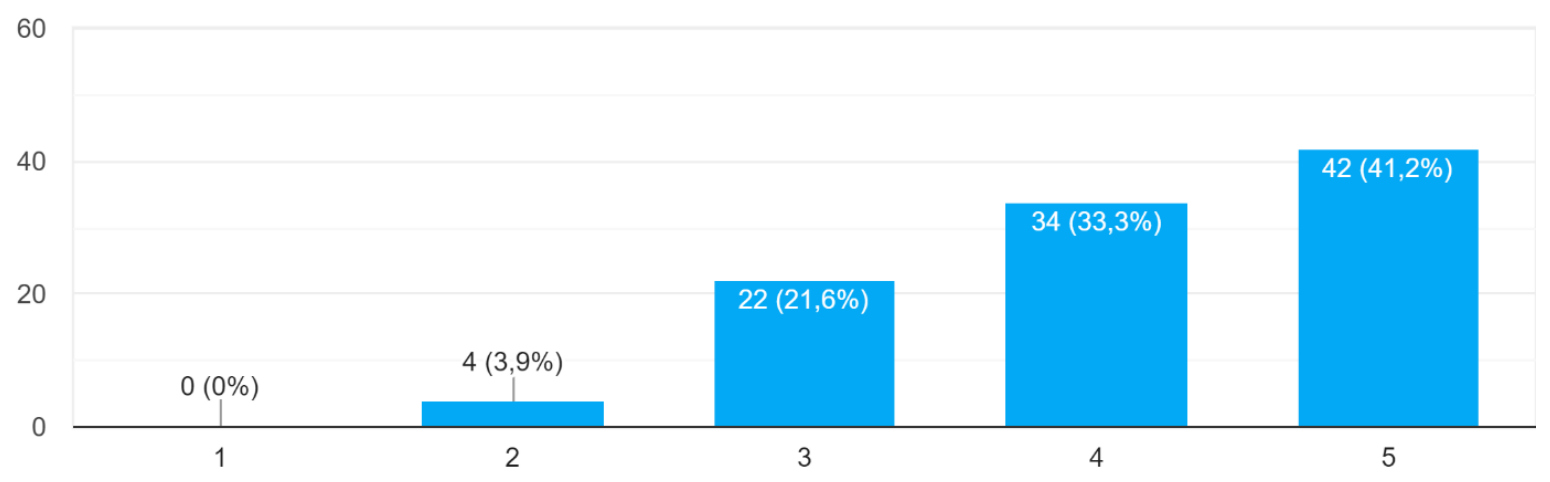

Figure 12. Perception of the importance of the study of methods and teaching of physical education.

Question 14. Do you think that physical activity carried out outdoors can contribute to achieving the development goals of primary school? $95.1 \%$ yes.

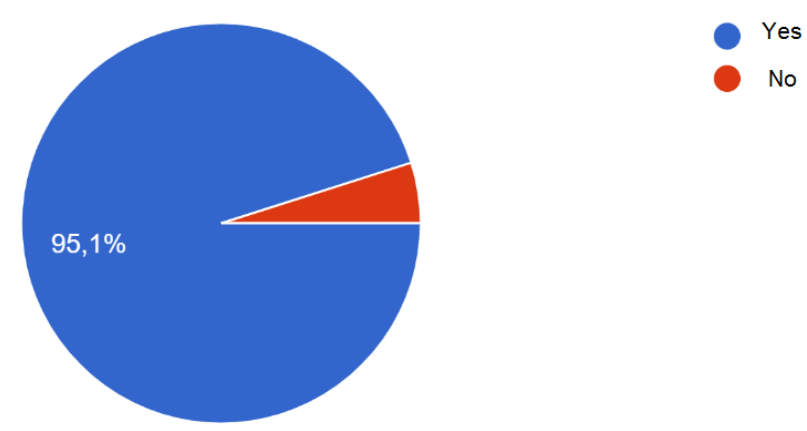

Figure. 13. Perception of the importance of outdoor physical activity to reach development goals of primary school.

Question 15. In your direct teaching experience, how was physical education in primary school implemented during the pandemic period? $3 \%$ regularly; $34 \%$ reduced hours; $63 \%$ not carried out.

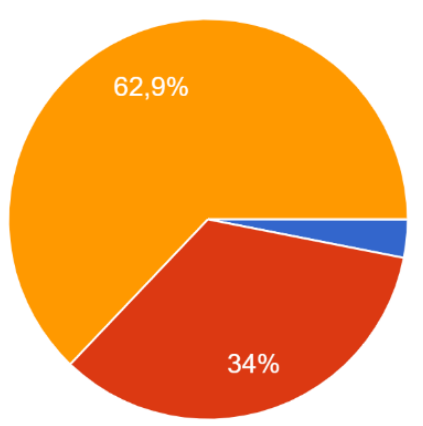

It was carried out regularly

It was carried out with a

reduction in hours and activities

It was not carried out

Figure 14. Frequency of physical education during the pandemic in primary school.

Question 16. Was physical education in DAD carried out? 7.1\% regularly; $41.8 \%$ reduced hours; $51 \%$ not carried out. 


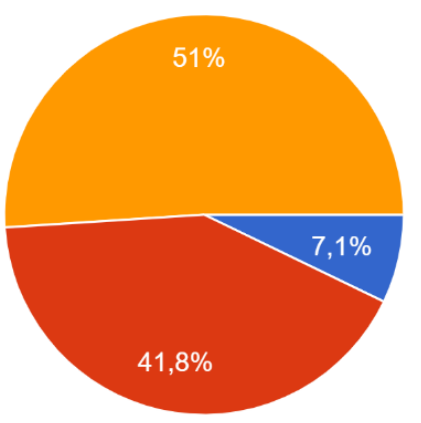

Regularly

With an hourly and activity reduction

It was not carried out

Figure 15. Frequency of physical education in DAD.

Question 17. Was face-to-face physical education carried out? 9.3\% regularly; $28.9 \%$ reduced hours; $61.9 \%$ not carried out.

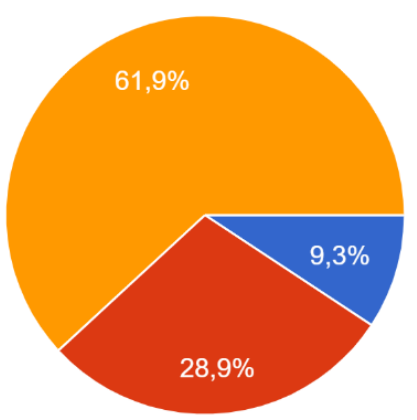

Regularly
With an hourly and activity reduction
It was not carried out

Figure 16. Frequency of face-to-face physical education.

Question 18. Do you see any differences between physical education before and after the pandemic? 93.8\% yes.
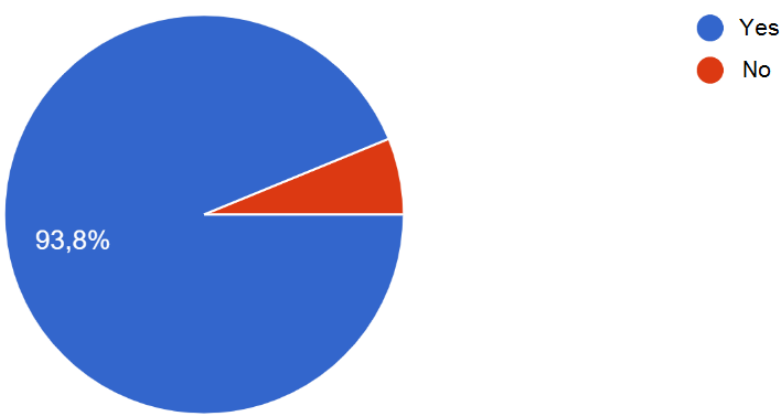

No

Figure 17. Perception on differences between physical education before and after the pandemic.

Question 19. Do you think it is possible to practice physical activities on a daily basis in primary school? $59.8 \%$ yes; 40.2 no. 

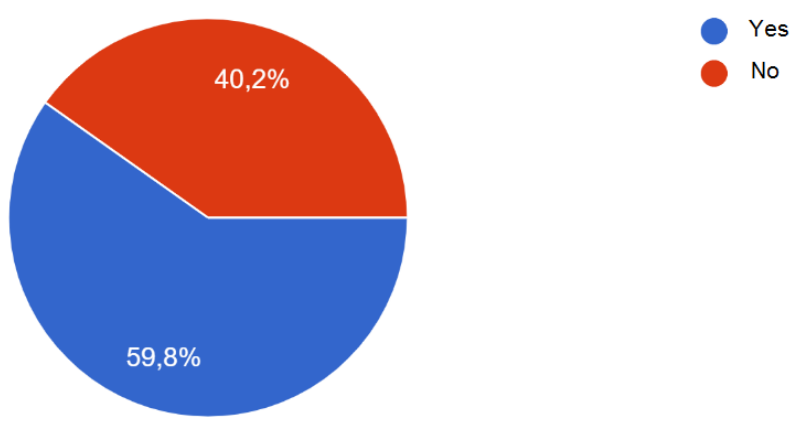

No

Figure 18. Perception of the possibility of practicing physical activity on a daily basis in primary school.

\section{Data on outdoor physical activities}

Question 20. In organizing experiences related to physical education in primary school, how much importance do you attach to outdoor activities? $83.3 \%$ high importance.

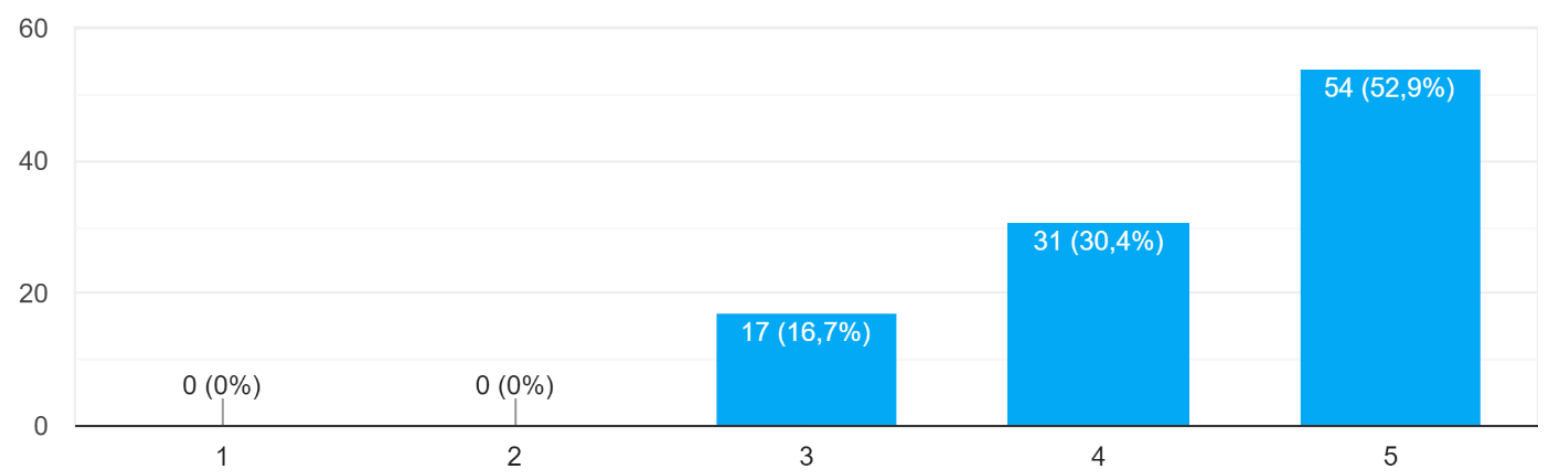

Figure 19. Perception of the importance of outdoor activity.

Question 21. Have you ever participated or conducted outdoor physical activity experiences (in parks or in the natural environment)? $37.3 \%$ yes; $62.7 \%$ no.

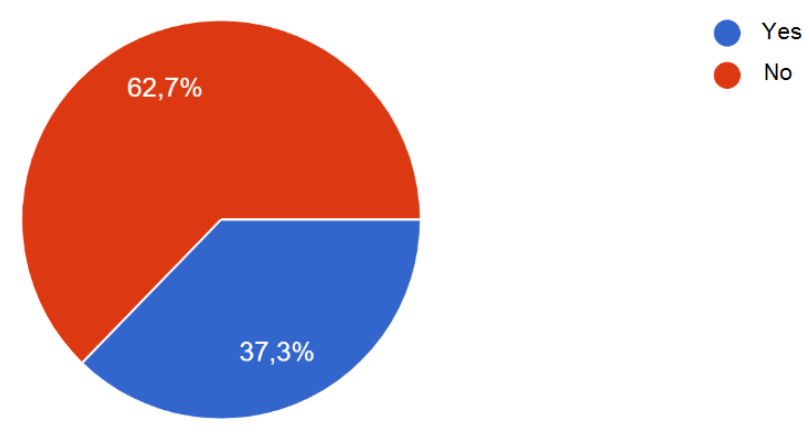

Figure 20. Experience in outdoor activities.

Question 22. Would you like to do outdoor physical activities in your teaching activity? $93.1 \%$ yes; $6.9 \%$ no. 


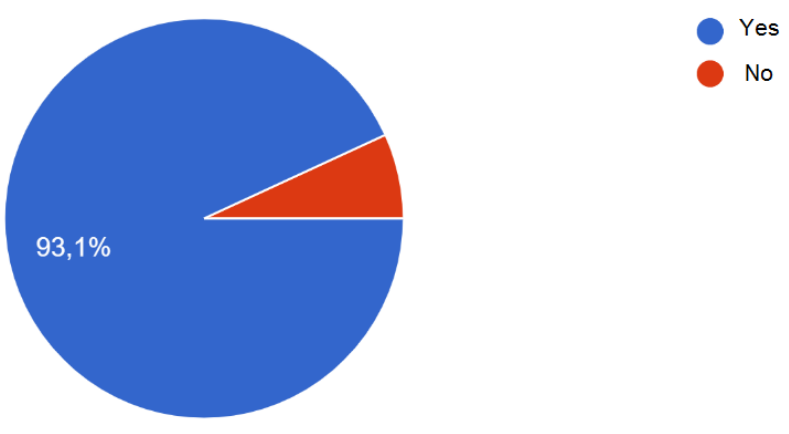

Figure 21. Perception on the possibility of practicing outdoor physical activity.

Question 23. Do you think your training is adequate to be able to carry out physical activities outdoors? $28.4 \%$ yes; $71.6 \%$ no.
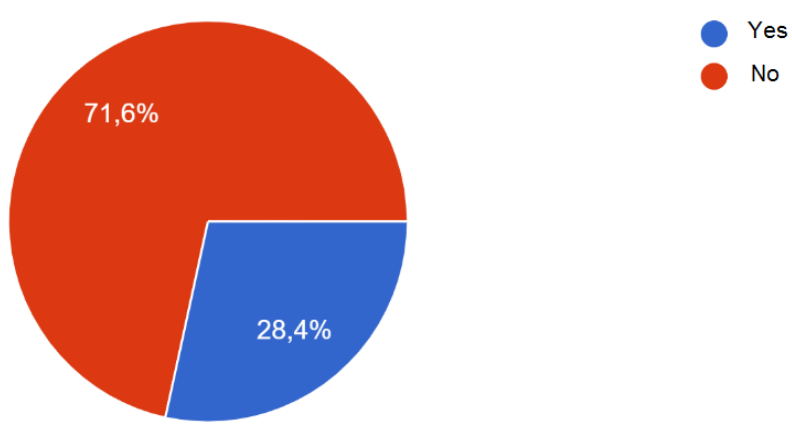

No

Figure 22. Perception of the adequacy of one's training to carry out outdoor activities.

Question 28. Do you think that the increase in outdoor physical activities, especially in primary school, can favour the resumption of teaching activities in the presence? $52 \%$ yes; $48 \%$ no.

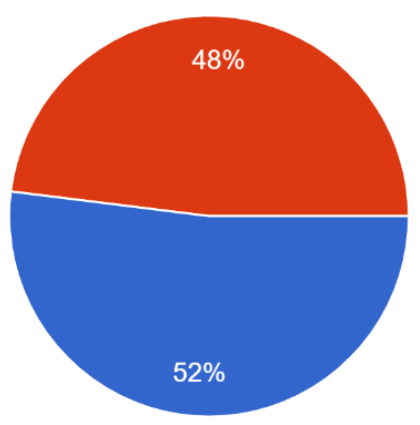

Yes
No

Figure 23. Perception on the possibility that outdoor activities can favour the resumption of didactic activities in presence.

In particular, from chi-square test emerges that there are the following relationships:

\section{Between being physically active (Question 6) and:}

(Question 11) the perceived influence of restrictions on physical activity. It seems that the cause of the physical inactivity of a part of the sample is linked to the current restrictions, while those who are partially 
active are because they have reduced their levels of activity, again due to the restrictions. Even those who currently hit 150 minutes have reduced physical activity levels (Fig 1-7; $p<.001$ ).

(Question 9) the presence of pedestrian paths, parks or outdoor sports facilities near your home. It seems that the presence of these structures has a positive effect on the practice of physical activity (Fig 1-6; $p<$ $.001)$.

Question 25) the perceived motivation in this pandemic period. It appears that those who are not physically active perceive low motivation, compared to those who engage in activities (Fig 1-9; $p<.001$ ).

(Question 27) the perception of the benefits induced by the activity against COVID-19. Those who train think that the practice of physical activity can have more beneficial effects than those who do not train (Fig 1-11; $p$ $<.01)$.

(Question 19) the possibility of practicing physical education on a daily basis in primary school. Physically active teachers appear to be more likely to practice physical education in primary school on a daily basis than inactive teachers (Fig 1-18; $p<.02$ ).

Inactivity could be due to current restrictions, the absence of pedestrian paths / parks / outdoor structures and low motivation. This is a problem because teachers who are inactive are also less predisposed to daily physical activity in the primary school and believe that the effects of physical activity against COVID-19 are not that high.

Between the perceived importance of the practice of physical and / or sports activity in daily life (Question 12) and:

(Question 13) the usefulness, for training purposes, of studying "Teaching methods of physical education". Those who perceive a greater importance of the practice of physical education in daily life, find it more useful to study "Teaching methods of physical education" (Fig 4-12; $p<.001$ ).

(Question 20) the perceived importance of outdoor activities. Those who perceive a greater importance of the practice of physical education in daily life, also perceive a greater importance of outdoor activities (Fig 4$19 ; p<.001)$.

What teachers think about the practice of physical activity in daily life is fundamental, because this can affect both the perception of the importance of studying teaching methods of physical education and the importance attributed to teaching/learning experiences conducted in outdoor environments.

Between the perceived motivation in practicing physical activity at this time (Question 25) and: (Question 11) the perception on the influence of restrictions on the quality / quantity of physical activity performed. Most of those who were more motivated reduced the practice of physical activity, unlike those who were less motivated who became mostly inactive (Fig 9-7; $p<.001$ ). Low motivation seems to affect the drop out of physical activity.

Between the possibility of practicing physical activity on a daily basis in primary school (Question 19) and:

(Question 28) the perception that the increase in outdoor physical activities, especially in primary school, can favour the resumption of teaching activities in presence. Most of those who believe it is possible to practice 
daily activities in primary school, also believe that outdoor activities can favour the resumption of teaching activities in presence (Fig 18-23; $p<.01$ ).

(Question 6) being physically active, as previously analysed (Fig 18-1; $p<.02$ ).

(Question 27) the perception that the practice of physical activity can have beneficial effects against COVID19. Those who believe it is possible to practice physical activity daily in primary school also believe that physical practice does not have many beneficial effects against COVID-19 (Fig 18-11; $p<.03$ ).

One of the issues, already encountered previously, is that those who do not want to practice physical activity daily in primary school are not physically active, moreover for the majority they believe that outdoor activities cannot encourage the return to teaching/learning activities in the presence and that the practice of physical activity does not have as many beneficial effects against COVID-19.

\section{Between the perception of the importance of outdoor activities (question 20) and:}

(Question 12) the perception of the importance of practicing physical and / or sports activity in daily life. Those who consider outdoor activity important, think that physical activity in daily life is very important (Fig 19-4; $p$ $<.001)$.

(Question 13) the perception of the usefulness, for the purposes of one's training, to study "Teaching methods of physical education". In fact, those who believe it is very important to carry out outdoor activities believe it is essential to study this subject (Fig 19-12; $p<.001$ ).

(Question 28) the perception that the increase in outdoor physical activities, especially in primary school, can encourage the return to teaching/learning activities in the presence. Those who believe it is important to carry out outdoor activities, think that the latter can certainly favour the resumption of activities (Fig 19-23; $p<.01$ ).

(Question 14) the perception that outdoor physical activity can contribute to achieving the development goals of primary school. Those who consider outdoor activity important, also think that it is able to contribute more to the achievement of primary school development goals, than those who believe the opposite (Fig 19-13; $p$ $<.02)$.

(Question 27) the perception that the practice of physical activity can have beneficial effects against COVID19. Those who consider outdoor activity important have a high perception of the beneficial effects of physical activity against COVID-19 (Fig 19-11; $p<.03$ ).

Those who think that outdoor activity is not very important, also believe that it in general is not too important in everyday life, that studying the teaching methods of physical education is quite useful, that outdoor activity it can favour the resumption of activities but not to the maximum, that it is not able to maximize the achievement of primary school development goals and that the beneficial effects of physical activity against COVID-19 are high, but not maximum.

\section{CONCLUSIONS}

The spread of the COVID-19 pandemic in Italy, in particular in some regions where the contagion rate has been particularly critical, it has caused the closure of schools for prolonged periods, so students and teachers have had to adapt their teaching/learning processes to distance learning. Schools, taking advantage of the 
available tools, have activated virtual classrooms and used different digital platforms to upload and share teaching materials. The teachers, with many difficulties, have tried to fill the serious lack of social relationship, using the technology currently available and attending training courses activated by schools in order to implement their knowledge and skills in the design of distance learning. For each discipline, it was problematic restructuring not only the learning contents and objectives but also the educational relationship. Physical education in primary school was the discipline that suffered, perhaps more than any other, from the lack of structured physical activities and, above all, of interpersonal relationships. The educational problems for physical education that emerged during the pandemic are basically due to the reduction of quantitative and qualitative opportunities to carry out structured and unstructured physical activities. In fact, social isolation, during the pandemic, increased physical inactivity, producing alarming data and repercussions on the health and wellness of individuals, highlighting the need to focus attention on adequate physical and sports education programs (D'Elia et al., 2020) capable of counteracting the trend of increasing sedentary lifestyle and physical inactivity further aggravated by the pandemic. It is therefore emerging to plan training courses for teachers in service who are capable of updating the teaching methods of physical education to the movement needs of children and adults; it is only by starting from teachers' awareness of the importance of physical experience that we could implement adequate physical and sports education programs useful for achieving primary school learning objectives.

\section{REFERENCES}

D'Elia F. (2020). Teachers' perspectives about contents and learning aim of physical education in Italian primary school. Journal of Human Sport and Exercise, 2020, 15(Proc2): S279-S288. https://doi.org/10.14198/ihse.2020.15.Proc2.19

D'Elia, F., Tortella, P., Sannicandro, I., D'Isanto, T. (2020) Design and teaching of physical education for children and youth, Journal of Human Sport and Exercise, 15 (4), pp. S1527-S1533. https://doi.org/10.14198/ihse.2020.15.Proc4.48

D'Elia, F. (2019a) The core curriculum of university training to teach physical education in Italy, Journal of Physical Education and Sport, 19, art. no. 256, pp. 1755-1758.

D'Elia, F. (2019b) The training of physical education teacher in primary school, Journal of Human Sport and Exercise, 14, pp. S100-S104. https://doi.org/10.14198//hse.2019.14.Proc1.12

D'Elia, F., D'Isanto, T. (2021) Body, movement, and outdoor education in pre-school during covid-19: Perceptions of future teachers during university training, Journal of Physical Education and Sport, 21, art. no. 66, pp. 580-584.

D'santo, T., D'Elia, F. (2021) Body, movement, and outdoor education in pre-school during the covid-19 pandemic: Perceptions of teachers, Journal of Physical Education and Sport, 21, art. no. 87, pp. 709713.

Invernizzi, P.L., Signorini, G., Colella, D., Raiola, G., Bosio, A., Scurati, R. (2020) Assessing rolling abilities in primary school children: Physical education specialists vs. generalists. International Journal of Environmental Research and Public Health, 17 (23), art. no. 8803, pp. 1-19. https://doi.org/10.3390/ijerph17238803

Raiola, G. (2011). A study on Italian primary school rules: Neurophysiological and didatics aspects in physical education and sport, Journal of Physical Education and Sport, 11 (2), pp. 43-48.

Raiola, G., Aliberti, S. (2021b) Outdoor sports and physical activity during social distancing by sports sciences and exercise course students at the university of Salerno, Journal of Physical Education and Sport, 21, art. no. 71, pp. 612-617. https://doi.org/10.7752/jpes.2021.s1071 
Raiola, G., Aliberti, S., Esposito, G., Altavilla, G., D'Isanto, T., D'Elia, F. (2020) How has the practice of physical activity changed during the covid-19 quarantine? a preliminary survey, Teoria ta Metodika Fizicnogo Vihovanna, 20 (4), pp. 242-247. https://doi.org/10.17309/tmfv.2020.4.07

Raiola, G., Di Domenico, F. (2021a) Physical and sports activity during the COVID-19 pandemic, Journal of Physical Education and Sport, 21, art. no. 49, pp. 477-482. https://doi.org/10.7752/jpes.2021.s1049 